\title{
An Unusual Presentation of Nasal Polyp Arising from Floor of Nasal Cavity
}

\author{
${ }^{1}$ Mahendra S Naik, ${ }^{2}$ Sulabha M Naik \\ ${ }^{1}$ Assistant Professor, Department of ENT, ASRAMS Medical College, Eluru, Andhra Pradesh, India \\ ${ }^{2}$ Associate Professor, Department of ENT, ASRAMS Medical College, Eluru, Andhra Pradesh, India
}

Correspondence: Sulabha M Naik, Associate Professor, Department of ENT, E-22, M MU Complex, Mullana-133203, Haryana India, e-mail: sulabha.naik@ gmail.com

\section{ABSTRACT}

Introduction: Nasal polyps are pedunculated, edematous, prolapsed mucosa of the paranasal sinuses. These polyps commonly arise around the ostia of the paranasal sinuses in the middle meatus.

Discussion: The commonest sites of polyp formation are the ethmoid sinuses and maxillary sinus. Rarely polyps may also arise from the other paranasal sinuses. Sites in the nasal mucosa other than the paranasal sinuses are very rare, though polyps arising from the septum have also been reported.

The etiology of nasal polyposis is believed to be due to an inflammatory reaction of the nasal and paranasal sinus mucosa. Conclusion: In addition to the theory of altered airway dynamics in the middle meatus, there also appears to be a link between polyp formation and preceding chronic inflammation. This is the most likely explanation for the origin of polyps in unusual sites.

We present here a case of a nasal polyp arising from the floor of the nasal cavity. There are no previous records or reports in literature of this unusual site of origin of a nasal polyp.

Keywords: Nasal polyps, Nasal mucosa, Nasal cavity.

\section{INTRODUCTION}

The term polyp is derived from G reek, meaning many footed (poly- many, pous- footed). ${ }^{1}$ A nasal polyp is defined as edematous, pedunculated mucosa of the paranasal sinuses which has prolapsed into the nasal cavity. These polyps commonly arise around the openings of the paranasal sinuses.

Ethmoid polyps are the most common and are believed to be allergic in origin.

The lining of the ethmoid sinuses prolapses in the middle meatus. ${ }^{2}$ These are bilateral, multiple and present anteriorly in the nose. A very rare instance of an isolated ethmoidal polyp arising from an anterior ethmoidal cell has been reported. ${ }^{3}$

The other common site of polyp formation is the maxillary sinus. The likely site of origin of antral polyps is believed to be from the lateral wall or floor of the antrum of highmore. A single polyp, arising from the maxillary sinus, can present in the nose and the choana. This polyp typically grows backward and presents as a choanal mass. The etiology is unknown and it probably represents a different disease entity.

Polyps also rarely occur in other sinuses. Polyps originating from the mucosa of the nasal septum though rare, have been reported. ${ }^{4}$ Polyps may arise from any respiratory epithelium of the nasal cavity.
W e present here, a case of an extremely rare occurrence of a nasal polyp, arising from the floor of the nasal cavity.

\section{CASE REPORT}

A 20-year-old housewife presented with right-sided nasal obstruction and rhinorrhea since 4 months. The discharge was watery, copious and blood stained. $\mathrm{N}$ asal obstruction began insidiously, gradually progressing to complete obstruction which was not relieved by any medication. She also complained of pain in and around right vestibule and right side of nose. She did not have any history of headache, sneezing, watering of eyes, etc. Clinical examination revealed a reddish mass in the right nostril, completely occluding the nasal cavity. The right nasal vestibule was enlarged with broadening of right side of nose (Figs 1 and 2). In this case, the polyp had resulted in broadening of the nostril, which is termed 'frog face' appearance. This cosmetic deformity is common in juvenile nasopharyngeal angiofibroma but is rarely produced by nasal polyps.

On probing, the mass appeared to originate from the nasal floor and was tender.

On postnasal examination, there was no extension of the mass into the chonae. No tenderness was elicited over the paranasal sinuses.

CT scan showed a soft tissue mass completely occluding the right nasal cavity without any involvement of any 


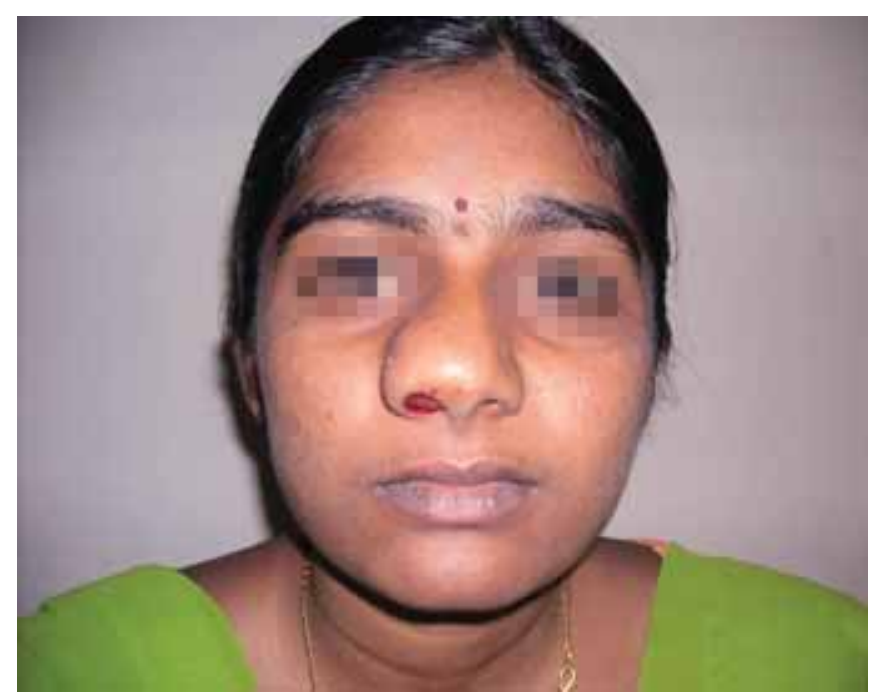

Fig. 1: Frontal view showing broadening of right side of nose

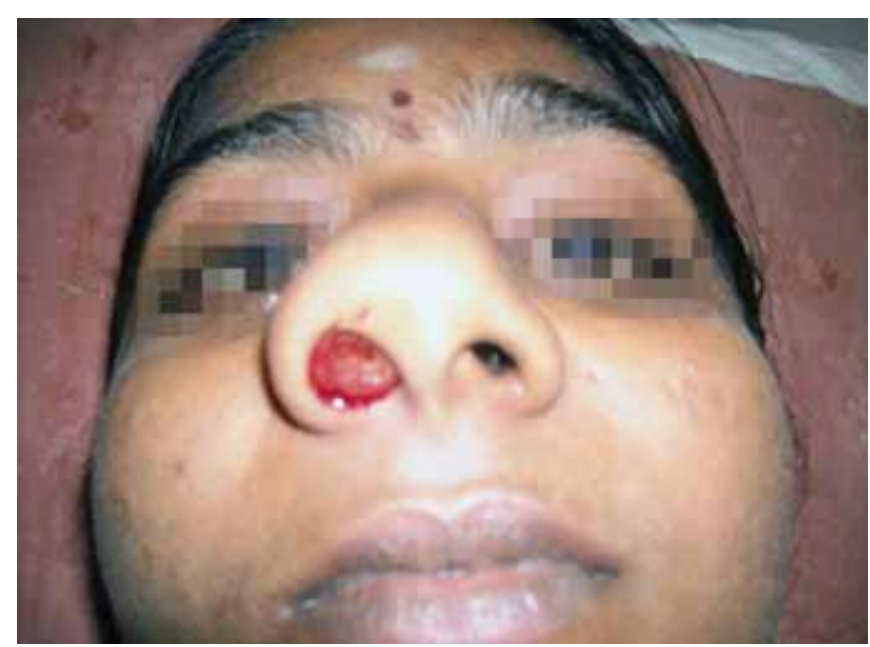

Fig. 2: Basal view showing polyp filling right nostril

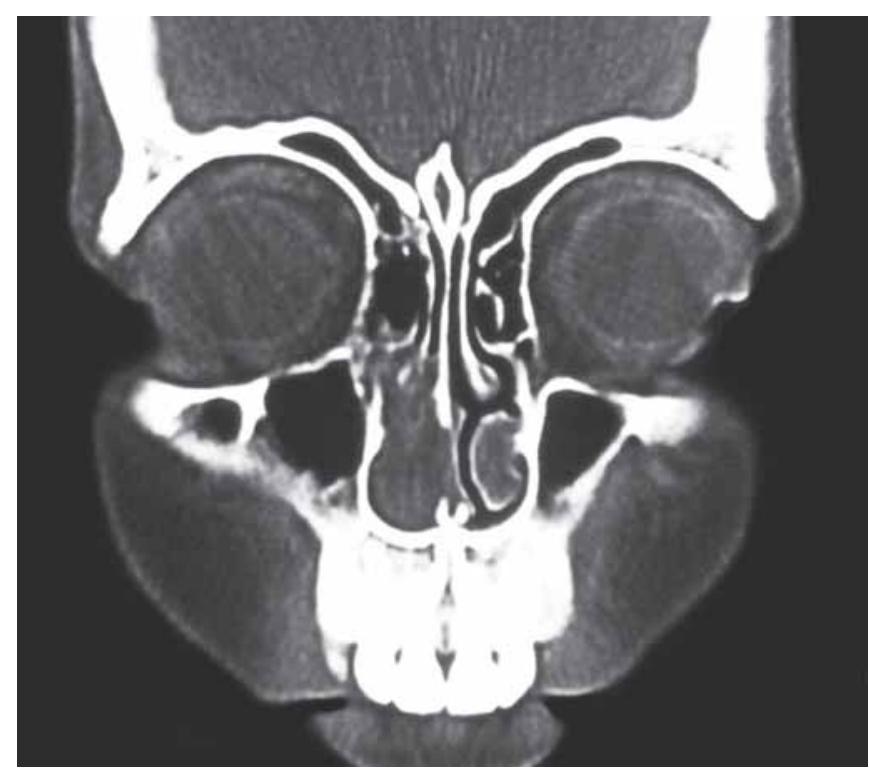

Fig. 3: CT scan coronal section showing mass in right nostril

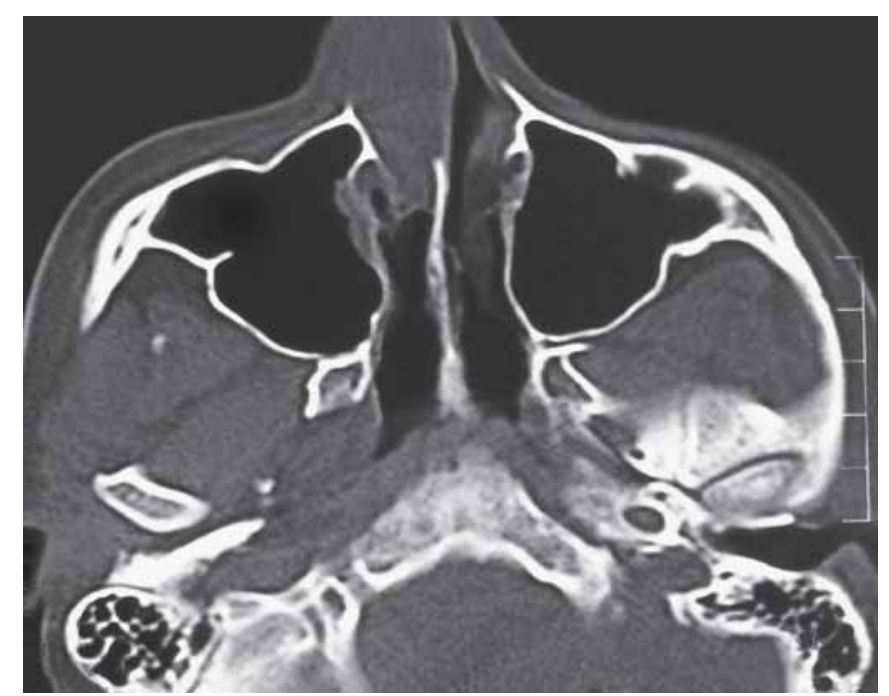

Fig. 4: CT scan axial section showing mass in right nostril with clear maxillary sinuses

paranasal sinuses (Figs 3 and 4). During surgery under GA, the mass was seen to arise from the nasal floor without any extension into the posterior choanae and sinuses. It was excised with cauterization of the base. The polyp measured $2.5 \mathrm{~cm}$ in length and $2 \mathrm{~cm}$ in diameter.

$\mathrm{H}$ istopathological examination revealed features typical of a nasal polyp.

The postoperative period was uneventful and the patient was discharged. There was no recurrence of the polyp 6 months after the surgery. Subsequently, the patient was lost to further follow-up.

\section{REVIEW OF LITERATURE}

As early as 1691, two cases of nasal polyps arising in the highmoro antrum were described by Fredrik Ruysch, a Dutch anatomist. $^{5}$

In 1891, Zuckerkandl from Graz, reported a case of a polyp arising from the maxillary sinus and coming out into the nose via a wide accessory ostium. ${ }^{6}$

In 1906, Gustav Killian from F reiburg, was the first to describe antrochoanal polyp. ${ }^{7}$

A ntrochoanal polyps are thus termed K illian's polyps.

$M$ axillary polyps and those arising in other sinuses (e.g. sphenochoanal polyp ${ }^{8}$ ) or the nasal septum are solitary.

Ethmoid polyps are nearly always multiple with a few rare exceptions. Eiji Y anagisawa and David J L esnik have reported a very rare occurrence of an isolated ethmoidal polyp arising from an anterior ethmoidal cell. ${ }^{3}$

A long standing nasal polyp can grow considerably in size. A maxillary polyp of dimensions $15 \mathrm{~cm}$ length and $5 \mathrm{~cm}$ diameter has been reported by $B$ hat and $V$ aidyanathan. ${ }^{5}$

\section{DISCUSSION}

While ethmoidal polyps are likely to be allergic in origin, polyp formation in other sinuses, particularly maxillary is unknown. 
A single predisposing cause cannot account for occurrence of nasal polyps in all patients. Polyp formation and growth are activated and promoted by an integrated involvement of muxcosal epithelium and inflammatory cells which in turn may be due to both infectious and noninfectious inflammation. ${ }^{9}$ Though the relationship between nasal polyps and chronic rhinosinusitis is debated, nasal polyposis is believed to be the result of an inflammatory reaction involving the nasal mucosa and that of the paranasal sinuses.

In a large number of patients with nasal polyposis and on examination of autopsy specimens, it has been shown that nasal polyps are mainly situated in the middle meatus. ${ }^{1}$ They commonly arise from the mucous membrane of the ostia, clefts and recesses of the sinuses, namely the osteomeatal complex.

In a study by Andrews AE, Bryson JM, Rowe-J ones $J M$, polyps were noted to be specifically originating from sites on the lateral nasal wall, such as the uncinate process, infundibulum, frontal recess and bulla ethmoidalis. ${ }^{10}$

Thus, most polyps originate from the middle meatus.

The reason for this is unknown and it may be possible that the 'touching mucous membranes' in a narrow osteomeatal complex results in release of proinflammatory cytokines from epithelial cells. A nother possibility is the dynamic of air currents and pressure in the nose.

In the rare instance when a polyp arises from an unusual site, such as the nasal septum ${ }^{4}$ or, as in this case, the nasal floor, the cause is still less known. B ased on the assumption that polyps arise al most al ways in proximity to an inflamed airway mucous membrane, it may be likely that preceding chronic inflammation has been the trigger for polyp formation.

\section{REFERENCES}

1. Chapter in book-Michael J Gleeson (Ed). Scott-Brown's Otorhinolaryngology: Head and Neck Surgery (7th ed):2: 1549-51.

2. Chapter in book-Kerr A, Booth J (Eds). Scott B rown's Otolaryngology (6th ed) Chapter 10, 4:1-16.

3. Y anagisawa Eiji, J L esnik D avid. Isolated polyp of the ethmoid sinus. Rhinoscopic Clinic Ear, Nose and Throat Journal Oct 2002.

4. Bailey Quentin. Choanal polyp arising from the posterior end of the nasal septum. The J ournal of Laryngology and Otology July 1979;93(07):735-36.

5. B hat $M, V$ aidyanathan $V$. Sausage in the throat. A case of giant antrochoanal polyp. J ournal of Clinical and Diagnostic R esearch [serial online] A pril 2010;4(2):2282-85.

6. Zuckerkandl E. Normale und pathologische A natomie der Nasenholme. V ienna 1892.

7. Killian G. The origin of choanal polyp. Lancet 1906;2:81-82.

8. A charya K, Pradhan B, Thapa N M, K hanal S. Sphenochoanal polyp. Nepalese J ournal of ENT Head and N eck Surgery. JanJ un 2010;1(1):21-23.

9. Stierna PL. Nasal polyps: Relationship to infection and inflammation. Allergy A sthma Proc Sep-Oct 1996;17(5): 251-57.

10. Andrews $A E$, Bryson JM, Rowe-J ones JM. Site of origin of nasal polyps: Relevance to pathogenesis and management. Rhinology Sep 2005;43(3):180-84. 